\title{
EFL Teacher Identity: Impact of Macro and Micro Contextual Factors in Education Reform Frame in Chile
}

\author{
Danisa Salinas ${ }^{1, *}$ \\ ${ }^{1}$ English Department, Faculty of Education, Universidad Andrés Bello- Viña del Ma, Chile \\ *Correspondence: English Department, Faculty of Education, Universidad Andrés Bello- Viña del Ma, Chile. E-mail: \\ danisa.salinas@unab.cl
}

Received: October 2, 2017

Accepted: November 7, $2017 \quad$ Online Published: November 29, 2017

doi:10.5430/wje.v7n6p1

URL: https://doi.org/10.5430/wje.v7n6p1

\begin{abstract}
The research aims at exploring how macro and micro contextual factors have influenced on the construction of English as a foreign language (EFL) teachers' identity in education reform contexts in Chile based on sociocultural theories. Grounded theory was used in the methodological design to analyse and categorize data utilizing the ATLAS.ti software. Deep semi-structured and focus group interviews were used to collect data, and twelve EFL teachers participated in the research. From a macro contextual environment, results show that educational demands turn into bureaucracy and a non-coherent EFL national curriculum which have weakened teachers' identity resulting in a sense of frustration and resignation. Micro contextual factors have emotional (appreciation, student/teacher bond, and work climate) and cognitive dimensions (in-service training) with a dual role - strengthening or weakening EFL teachers' identities.
\end{abstract}

Keywords: education reform; EFL teacher identity; micro and macro contextual factors, grounded theory

\section{Introduction}

Teaching English as a foreign language is a priority in education reforms in many non-English speaking countries due to the outstanding role the language has achieved in global communication (Bonilla \& Tejeda-Sánchez, 2016). When Chile became member of the OECD (Organization for Economic Cooperation and Development) in 2010, the teaching of English as a foreign language took a prominent role in Chile's education system.

Teacher identity (TI) is an essential topic to consider in the context of globalization (Menter, 2010) due to the impact social changes have on education. EFL teachers' identity construction has been studied from different perspective and purposes mainly because teachers have to deal with a process of adoption and adaptation having an impact upon their professional identities (Day et al., 2006). That is why teacher identity has become an independent field of study in the last two decades (Beijaard et al., 2004) reporting that teachers' work has been reshaped in similar ways around the world (Robertson, 2000). Chile is not an exception to this phenomenon.

Since social and political contextual factors play a role on educational systems, many studies in the field of second language teachers' identity have their theoretical foundations within the sociocultural theory (Chacón, 2010; Cross, 2006; Katsuno, 2012; Kim \& Dang, 2013; Flum \& Kaplan, 2012; Tsui, 2007). The present investigation lies at the theoretical foundations of the sociocultural theory and at the methodological foundations of the grounded theory (Straus \& Corbin, 1998).

The purpose of the present investigation is to explore how micro and macro contextual factors impact on EFL teachers' identity in an education reform-driven context in Chile.

\subsection{School System in Chile and the Teaching of English in Reform Contexts}

The educational system in Chile is regulated by the 2009 General Law of Education (LGE) which is focused on equity and quality. This law replaced the Organic Constitutional Law of Teaching (LOCE) promulgated in 1990 by the military government whose main objective, among others, was to reach coverage to all social layers in the country. The educational system in Chile is regulated by the 2009 General Law of Education (LGE) which is focused 
on equity and quality. This law replaced the Organic Constitutional Law of Teaching (LOCE) promulgated in 1990 by the military government whose main objective, among others, was to reach coverage to all social layers in the country.

Both laws establish that the State has the responsibility to finance the school education for every child in the country, but the school administration has been in charge of the municipalities and subsidized-private schools. In both cases, the state has provided the financial resources through a voucher per student. Within this structure, there is a small group of self-financed private schools in the country $(7 \%)$. Currently, the education reform is starting a process to have just municipal schools administered directly by the state.

The national standardized Measuring System of the Quality of Education (SIMCE) in the school system was kept by both laws. Students are assessed in various subjects (Mathematics, Spanish, Science, Physical Education and English as a Foreign Language) in different stages of their school years. Some students (samples) are also internationally assessed through PISA (Program for International Student Assessment) and TIMSS (Trends in International Mathematics and Science Study). In 2011, all students in the 11th year took the first SIMCE in English.

The programs of study in all subject areas in the national curriculum were changed within the frame of the last two reforms (1990 and 2006) in terms of contents and objectives. The English subject has particularly been modified since it has a worldwide predominant place in education and in society. In 1999, the Ministry of Education declared that the teaching of English had to start at an earlier stage in the national curriculum and English became compulsory as from 5th grade (previously from levels 7 th to 12th). The publication of the new curricular bases in 2013 was the latest adjustments made by the Ministry stating that all students should reach level B1 according to the Common European Framework (CEF). The most significant change, however, is the methodological approaches teachers had to adopt, moving from the traditional grammatical/lexical approach to a communicative/interactive teaching method.

\subsection{Teacher Identity}

\subsubsection{Theoretical Foundations}

The predominant theoretical foundation used in identity formation is the sociocultural theory sheltering sociological and psychological foundations from which interaction between an individual and society is the main focus. Personal thought, perception and experience are related to the individual (Menter, 2010); whereas social institutions, communities and cultures are related to society.

Several notions emerge from the psychological and sociological perspective when conceptualizing identity from the sociocultural theory. Symbols, signs, language, meanings, higher mental functions, mediation and social interaction are the fundamental concepts within the socio-cultural theory (Mead, 1934; Erickson in Penuel \& Wertsch, 1995; Blumer, 1969; Vigotsky, 1978, Wenger, 1998). In any community, society, or culture there are symbols and/or signs which are given certain meaning by the individual through his/her higher mental functions and the mediation process employed when interacting with that society, community, or culture.

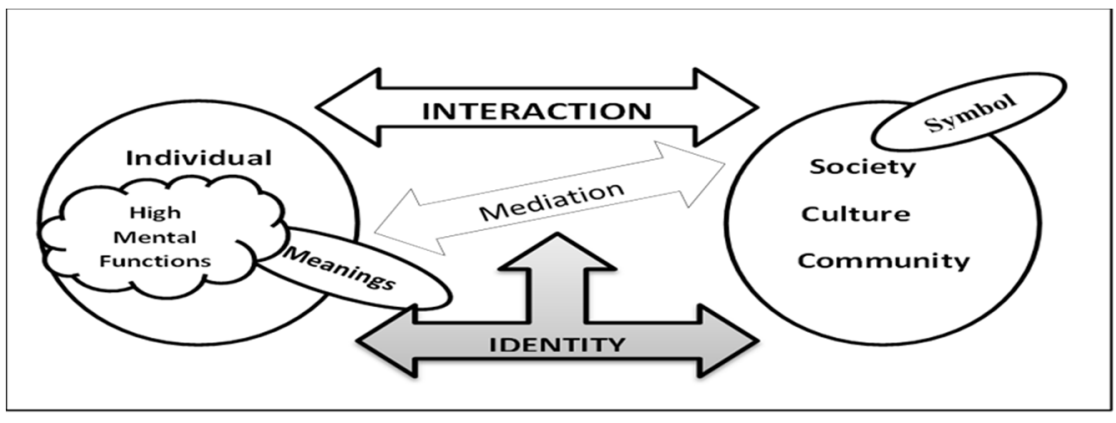

Figure 1. Fundamental Concepts in Identity Construction Based on Sociocultural Theories

From the educational perspective, these same theoretical conceptions constitute the platform for teacher identity (TI) research. The majority of TI research shares these two major components: the context (society, community, culture) and the individual (person). The reciprocal and dynamic interaction of these factors shapes teacher identity through time (Belmant et al., 2015, Olsen, 2008). Teacher identity, then, is a collection of influences and effects from previous construct of self, immediate contexts, human relationships and meaning systems that teachers negotiate at a 
given moment and contexts (Olsen, 2008).

\subsubsection{Contextual Factors in Teacher Identity Construction}

Various internal and external factors are involved in the construction of teacher identity which have allowed researchers investigate TI from a range of perspectives. TI has developed as an independent research area (Beijaard, et al. 2004) and studies in this field have significantly increased (Beauchamp \& Thomas, 2009); for example initial and continuing professional development (Chong, 2011; Hoban, 2007; Olsen, 2008; Prytula, 2012; Sachs, 2005), the impact of contextual factors (Smagorinsky et al., 2004), novice teachers' experiences (Chong, 2011), complexity of EFL teacher's identity formation (Tsui, 2007), educational reform impact on teacher identity (Day, 2002; Hoffman-Kipp, 2008), among others.

Macro contextual factors, such as political and social changes, also bring implications to identity construction, "teacher identity [is] very directly [related] to questions of policy, politics and governance" (Menter, 2010, p. 35). Education reforms are taking place in many countries and they have an impact on teachers' identities from emotional and cognitive perspectives (Day, 2002), challenging their identities. Many teachers think that reforms undermine their professionalism (Day, 2002), that they must build their identities on demands for changes and reforms; if they do not, they have conflicts in their working environments and reduce their self-confidence Avalos (2010). Hall and McGinity (2015) explored the dramatic implications that the shift to neo-liberal education policies had on teachers' professional identity.

\subsubsection{EFL Teacher Identity}

Among EFL teacher identity research, some outstanding studies have been designed under the umbrella of the sociocultural theory. The school environment, professional experience, impact of national assessment, and membership and meaning negotiation are the specific topics addressed in the EFL teacher identity research (Chacón, 2010; Cross, 2006; Katsuno, 2012; Kim \& Dang, 2013; Flum \& Kaplan, 2012; Mora et al., 2013; Tsui, 2007).

Understanding language teacher identity from a sociocultural perspective, Varghese (2005) considers both specific contextual influences from the teacher and external contextual influences from the environment. She defines EFL teacher identity as "multiple, shifting, and in conflict... [and it] is crucially related to social, cultural, and political context." (Varghese, 2005, p.35). The present research mirrors this theoretical sociocultural perspective for EFL teacher identity and will pursue this definition along the study through a qualitative research methodology to answer the following question:

How do micro and macro contextual factors impact on EFL teacher identity in a reform and changing/demanding education environment?

\section{Method}

\subsection{Grounded Theory}

The study was designed to explore how micro and macro reform-driven contexts impact on EFL teachers' identities. To capture this process, a qualitative research paradigm was used based on Strauss \& Corbin's grounded theory (1998). This methodological strategy allows the researcher to generate, discover or complement a theory through a process that starts from the description of the phenomena and its conceptual ordering to theorization (Strauss \& Corbin, 1998).

"Both theory and data analysis demand interpretation based on systematic exploration" (Strauss \& Corbin, 1998, p. 17) to capture the meanings the individuals give to their interactions and the phenomenon. The inductive nature of grounded theory allows a resulting theory that emerges from the data, from the basis or the ground; in this case, from EFL teachers' meaning systems and interactions.

\subsection{Data Collection Procedure}

Data collection procedure had 2 phases. During the first stage six EFL teachers were interviewed 3 times each. These individual semi-structured interviews lasted 50 to 60 minutes each. There was a two-month interval between the interviews for each teacher (the complete procedure took seven months). The eighteen interviews were audio recorded and later transcribed. These interviews provided teachers' in-depth discussions of their personal teaching perspective in relation to their closest working environment and broader educational contexts. Kvale (1996) claims that semi-structured interviews are mainly used to understand every-day life topics from the subjects' perspectives. The guiding topics in the individual interviews were (i) self-perceptions as EFL teachers in the school where they work, (ii) perceptions of demands of the present educational policies in Chile and their effect in their teaching 
practices, and (iii) their teaching histories.

The second stage of the data collection procedure consisted on a focus group discussion. Another group of six teachers participated in the focus group. The discussion and interactions were focused on the various topics and categories that emerged from the open and axial coding during the data analysis procedure carried out with data from the first group of teachers. The purpose of the focus group was to triangulate the results obtained from the semi-structured interviews. During the second phase, a great amount of data related to attitude, values and opinions was obtained in a short period of time.

The interviews took place in the teachers' working environment, the school where they worked. Some interviews were scheduled during their planning hours and others after the school working day. The focus-group meeting took place at the university where the researcher works.

The participants' native language (Spanish) was used in both, the interviews and focus group, to have spontaneous conversations between the interviewer and interviewees. The quotes presented in the results were translated into English.

\subsection{Participants}

Twelve EFL teachers were contacted by the researcher considering five factors that were considered relevant to obtain a broad lens of the impact that micro and macro educational reform contexts have on their teacher identity: (i) type of school administration they were currently working, (ii) grade where they taught, (iii) teaching experience, (iv) gender and (v) nationality.

The school administration model in Chile (municipal, subsidized, and private schools) was part of the educational reform that started more than two decades ago and is a contraversial issue in today's educational system in Chile. For both, semi-structured interviews, and focus group, one third of the teachers were working in subsidized schools, one third in municipal and one third in private schools at the time of the research.

Teaching English in elementary school is one of the most recent policies in the reform context. Teachers were chosen considering the school grade they were working in. Half of the teachers were working in the first years (elementary school) and the other half was working in secondary schools.

The range of the teaching experience is also a relevant factor for the present study, it is important to have the perception from teachers having diverse teaching experience to avoid vias in relation to the process they have gone through during reform implamantations; novice teachers were not considered, though, due to the various new professional experiences they have to go through when starting their teaching career. The years of participants' teaching experience ranged from 5 to 15 years.

Most teachers in Chile are female, so most of the participants were female (10 out of 12).

Nationality is onother relevant factor in teacher identity formation in the present study. All participant teachers are Chilean and studied in Chilean universities to become EFL teachers. Teachers being native speakers of English were not considered because the percentage of native EFL teachers teaching in schools in Chile is very low.

\subsection{Data Analysis: Grounded Theory}

In line with a grounded theory approach (Strauss \& Corbin, 1998), the data analysis began with a systematic inductive process through coding phases: open, axial, and selective coding. The analysis and interpretation of a vast data emerges from the teachers' statements produced in the interviews and focus group and the meaning they give to the interactions with their micro and macro contexts.

The Atlas.ti software was used to support this analysis, especially during the coding phases when obtaining the units of meaning with a focus on how EFL teachers' identities were influenced or shaped by micro and macro contextual factors. The software has a Hermeneutic Unit where all the transcribed data or primary documents, quotations, codes, memorandums, family codes and net nodes are stored in different files with their corresponding labels and connections.

The open coding refers to the analytical process through which concepts from the subjects' quotes are identified and labelled with words or phrases such as "teacher/student bond", "working conditions" or "appreciation". Many categories emerged from the open coding and were stored with their properties and dimensions. When examining the units of meaning by finding the similarities and differences in the properties through the axial coding, some codes were re-grouped under more abstract concepts and the number of categories was reduced. The relationships among these resulting categories provide the story line and explanation of the core concept or the main category (selective 
coding) which settles the basis to address the research question.

The main categories obtained in the selective coding process are emotional and cognitive dimensions and educational authorities' demands.

\section{Results}

The purpose of the present research is to explore how micro and macro contextual factors impact on EFL teachers' identities in reform-driven contexts.

\subsection{Micro Contextual Factors: Emotional and Cognitive Dimensions}

The resulting micro conceptual factors influencing EFL teacher identity mainly have two dimensions: emotional cognitive.

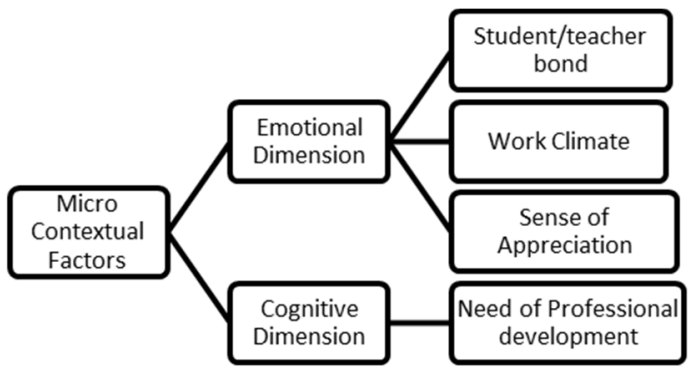

Figure 2. Micro Contextual Factors

The closest factors linked to teachers' tasks in their working place is the school environment. Teachers' working place is obviously the school; however, what is generally known about the term 'school' includes a broad amalgam of active and passive actors as well as tangible and intangible factors (school authorities, teaching and administrative staff, students, cleaning staff, parents, school culture, atmosphere, mission, etc.) from which just some of them had relevance in the teachers' meaning system in the present study. The student/teacher bond, work climate, in-service training, English department, working conditions and school demands are the micro contextual factors that influence EFL teachers and can be classified in two dimensions: cognitive and emotional or rational or non-rational (Atkinson, 2004).

The characterization of teachers' identities from the emotional dimension focus on teachers' value to the affective relationship with different school members; that is the student/teacher bond and work climate. From a cognitive dimension, the need of professional development and the sense of either commitment or detachment in relation to their working conditions and school demands are the main characteristics influencing their teacher identity. The value of affective relationship and the sense of commitment or detachment (emotional dimension), the need of professional development (cognitive dimension) are described in the following sections.

\subsubsection{Emotional Dimension in EFL TI: Affective Relationships and a Sense of Commitment or Detachment}

Student/teacher bond, work climate, sense of appreciation from school members and working conditions are the core factors that build upon the emotional dimension in teachers' identity.

The student/teacher bond refers to the dialogic interaction between the student and the teacher in the workplace environment. Different aspects are involved in this interaction, from closeness between student-teacher to the justification of students' disinterest in learning English.

T6: "The relationship with my students is the most important issue for me..., to know what they lack, their experiences, their worries, likes and dislikes."

T5: “... and how I am going to ask a student who has drug or alcoholic problems at home or a student who is pregnant to have good results in the SIMCE in English."

Students' attitudes interfering their own learning process have different causes, from a shy student to a drugged one. However, teachers' dedication to students and understanding of whatever reasons the student has for not advancing in their learning process reflects a sense of social responsibility that the teacher has been developing.

The second factor influencing on teachers' identity from the emotional perspective is the work climate in their school culture and refers to the social interpersonal relationship among the teaching staff on a daily work routine. 
T1: “...I would say that here what has mostly helped me is the working atmosphere. From the first time, I came here everybody greets you with a good morning, how are you? or what do you need?".

Another teacher quotes:

T6: “...there are teachers here who do not even say good morning."

For teachers, good relationship at school is reflected through a greeting, sharing a coffee, willingness to help and respect. The staff room seems to be a key factor in any school culture (Day, 2002). A good atmosphere with colleagues is a cause of motivation in teachers' identities and emotions play a fundamental role in educational environments (Esteve, 2006).

A third factor in the school environment linked to the affective perspective influencing on teacher identity is 'appreciations'. Teachers value the recognition of their work from students and directors.

T1: "...when receiving congratulation from my boss for my work and contributions to the school makes the difference."

T5: "if you see that students thank you for the time you devote to them... when trying to look for the best way to teach."

As noted from the quotes, the main characteristic in 'appreciation' is the concrete recognition to teachers' work, particularly from students.

The fourth factor related to the affective perspective is teachers' working conditions and demands that result in a sense of commitment or detachment to the institution. A clear dissimilarity is detected among teachers depending on the type of school they work. Young teachers working in municipal schools currently have a fixed-term contract (lasting only a year) which makes them experience job insecurity; whereas teachers who have a permanent contract (private and some subsidized school teachers), have a sense of commitment to their institution. In private and some subsidized schools, teachers' working hours consider time for planning lessons and/or meetings; whereas teachers working in municipal schools have many courses and the working hours generally do not consider time for meetings or planning lessons. All these disadvantages cause a sense of detachment to the institution. Pedagogical resources are available in private and some subsidized schools, the only resource municipal school teachers have is the textbook provided by the ministry. For the EFL teacher, technological resources are essential, together with posters, cards, authentic readings, books, among many others to properly teach the language. A teacher complained:

FG: "I had to buy my own data projector!.... and now I have to get my own speakers because they have only one set for all the teachers here."

Teachers working in private and some in subsidized schools have permanent contract, pedagogical resources at school, and time to plan their lessons within their working hours. Consequently, these teachers develop a sense of self-confidence, commitment to and engagement with their schools or working places. On the other hand, teachers who work in municipal and some subsidized schools do not have the same benefits and develop a sense of insecurity, demotivation, and detachment, what results in a weaker TI.

\subsubsection{Cognitive Dimension of EFL TI: Need for Professional Development}

Most EFL teachers in the present study see the need to update their knowledge in the methodological area to use appropriate approaches according to the new national curriculum requirements within the education reform context as well as methods to teach young learners (elementary school children). Teachers perceive that they are isolated when they do not take part in professional training; they do not know if they are doing things accordingly, which plays against their self-confidence from a cognitive perspective in teacher identity.

T4: "I would appreciate we had from time to time some kind of training in the use of technology in our classes for example."

T3: "If I want to do any training related to pedagogy or EFL methodologies or counselling, I have to pay for it."

The English department, in a way, compensates teachers' lack of in-service training. The English department is defined as a micro community within the educational institution where all teachers of English interact with pedagogical purposes. One of its most recurrent features for participants is 'team work'. Teachers together develop multitasks (sharing pedagogical practices, feedback, planning, and elaborating tests) focusing on a unique objective: students' achievements.

T3: "...team work is vital for me, it is positive, constructive because all teachers contribute, and one learns about personal weaknesses and strengths, this way we complement with each other; this has been great for me." 
Teachers who do not have English department where they work recognize it is an obstacle. Teachers' pedagogical interactions as mutual engagement (Wenger, 1998) build up knowledge and meanings in a dynamic and cooperative way resulting in a learning community. Through these interactions, EFL teachers develop a sense of self-confidence and motivation that shape a stronger TI.

\subsection{Macro Contextual Factors: Educational Authorities'Demands}

The macro contextual factors influencing EFL teacher identity mainly originate from the Educational authorities' demands.

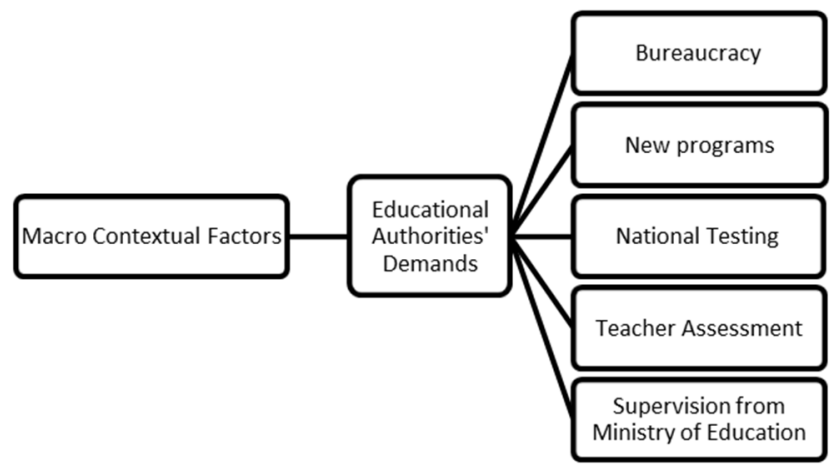

Figure 3. Macro Contextual Factors

Teachers' administrative demands in schools derive from the educational authorities' requirements in relation to new curriculum implementations in the context of reform. These demands constitute the macro contextual factors that influence on teachers' identities.

When proposing the topic about the obligations teachers should comply with and their opinions and feelings related to it, most teachers stated the "school's demands come from the Ministry and it puts pressure on schools and then on us." The 'bureaucratic' demands from school, as teachers call the administrative demands, mainly originate from the State educational authorities and the educational institutions just respond to these requirements.

The specific demands teachers in the present study have to cope with are related to the fulfilment of programs from the new national curriculum, multiple administrative tasks, the accomplishment of the standardized national evaluation in English (SIMCE), teacher assessment, and ministry supervision.

Fulfilments of the national curriculum and administrative tasks refer to the Ministry supervision. The supervisor checks official documents, institutional documents, class books, teacher's year planning and assessment, which have to be aligned with the national curriculum. He/she also checks children's attendance (to verify if vouchers are in accordance to what was requested in the budget), the register of each class objective, content of each class and assessment. It is important to mention that only municipal and subsidized schools are directly and constantly supervised.

T1: "I feel there is a lot of demand in relation to the plans and study programs, with the class book, with what the ministry requirements and we forget about teaching, which is the most important issue for a teacher."

The SIMCE in English test, with international standards, measures the minimum linguistic competences the students have to achieve in the language to have international certification and has been applied every two years since 2011. Teachers in 11th year feel extra pressure since they feel they have to be accountable. However, there is a mismatch between the English national curriculum (developing the four linguistic skills) and the SIMCE test that is focused on evaluating only listening and reading skills.

Excessive paper work load and a non-coherent curriculum cause tension, disenchantment, and a sense of frustration and resignation that weakens teachers' identity, especially on teachers who work in municipal and some subsidized schools. On the other hand, teachers working in private schools are challenged to achieve high academic standards, but at the same time are supported by schools, resulting in teachers with a sense of achievement and motivated.

\section{Concluding Discussion}

The purpose of the present investigation was to explore how micro and macro contextual factors impact on EFL 
teachers' identity in a changing/demanding educational environment in Chile. From the macro contextual environment, educational demands turn into bureaucracy and a non-coherent EFL national curriculum which have weakened teachers' identity resulting in a sense of frustration and resignation. On the other hand, micro contextual factors have emotional (appreciation and student/teacher bond) and cognitive dimensions (work conditions and in-service training) with a dual role - strengthening or weakening EFL teachers' identities depending on the school administration where they work.

\subsection{Bureaucracy as Macro Contextual Factor}

Macro contextual factors are directly related to the educational demands from the educational authorities and these derive from reform changes. Teachers in the present study manifested they had to fulfil multiple and excessive administrative tasks and cope with the new national non-coherent national curriculum, the students' national standardized test, and school inspection. This results in periods of destabilization and increased workload because of "externally-imposed curricula, management innovations, and performance assessment systems that have often been poorly implemented" (Day, 2012, p. 8). The dimensions and emphasis of these educational demands and innovations in the present study vary depending on the meaning system that emerge from the teachers' interactions and how they impact on their identity.

All teachers need to perform administrative tasks; however, excessive load of tasks for teachers working in municipal and subsidized schools plays against their teaching time and time availability for methodological innovations and class preparation, as they mention "when are we going to talk ... about teaching strategies? What time are we going to teach?". Teachers work under 'useless' pressure, not exactly teaching, which goes against what their main role as teachers and the result is a weak teacher identity and therefore low students' performance. As Hall and McGinity (2015) state, teachers nowadays are inserted in policy contexts ruled by managerialism and measurement in neoliberal contexts and feel pressed to comply with tasks that move them away from their teaching tasks in the classroom.

On the other hand, teachers working in private schools do not have the pressure from educational policies; instead they have direct demands from their working environment (Avalos, 2010). These teachers have to be accountable for the students' linguistic competences, which go beyond the national standard test (SIMCE in English). In private schools, administrative tasks do not put pressure on teachers; instead, they are required to have students achieve high academic standards in the foreign language. Thus, the meaning these teachers negotiate through their interactions with the school authority is positive mainly because they are not taken away from their teaching tasks and do what they are supposed to do: to teach students. The consequence on teacher identity is mirrored in agency, commitment, motivation, and accountability of their teaching practice resulting in high students' performance.

Macro contextual factors have a negative impact on teachers working in municipal and some subsidized schools. The nature of these teachers' interactions with the educational authorities are represented through obstacles, contradictions, pressure and tension which in turn causes disenchantment, demotivation, frustration, hopelessness, and finally resignation that weakens teachers' identity. Excessive bureaucratic overload (Day, 2012) takes time to fulfil teaching tasks. These teachers, then, tend to construct a weaker teacher identity because they perceive a distance between their identities and the ones imposed by institutions (Ávalos, 2012). It seems that education reforms challenge teachers' identities and have negative implications regardless the benefits and intentions that reforms would bring to quality in education.

\subsection{Micro Contextual Factors: Lights and Shadows}

Micro contextual factors have two dimensions - cognitive and emotional or affective. Teachers' professional identities are revealed through their cognition, emotion and interactions in their environment, it means that thoughts, emotions and actions together construct self (Zembylas, 2003). The cognitive dimension in the present study in relation to microcontextual factors contemplate teachers' thought on their work conditions and in-service training. On the other hand, teachers' affective relationships linked to an emotional dimension considers work climate, students/teacher bond, appreciations and working conditions. As Day (2006) points out, there is a cognitive part and an emotional part in teachers' identities that are always affected by education reforms.

Teachers consider the English department as a micro learning community or community of practice (Wenger, 1998) that somehow responds to the lack of or scarce in-service training. Even though the ministry has driven in-service programs to support teachers' work, such as the PIAP, it seems that this support does not get to the basics: school teachers. Teachers claim they need in-service training to cope with the changes and demands derived from the educational reform, especially in the teaching of English as a foreign language. When professional development 
arises from teachers' interest, they are more committed to it and changes that emerge are long-lasting and are transferred to the language classroom (Mora et al., 2013). Private and some subsidized schools do have an English department which comes to compensate lack of in-service training since teachers recognize that through interactions they develop professionally.

Students/teacher bond, appreciations and good working climate and conditions are positively and emotionally imbued so they constitute the balance in teachers' identity construction. As stated by Beauchamp \& Thomas (2009), the nature of teaching relates to human interactions, so professional identity has to be emotional. The affective relationships with students and colleagues play a prominent role and have a positive influence on teachers' identities. A significant and ongoing part of being a teacher (Day et al., 2006) is experiencing emotions in their working environment (Esteve, 2006). The caring aspect of teaching is a particular perspective that is being considered in teacher identity construction nowadays (O'Connor, 2007) and together with a good relationship with colleagues have a positive impact on teachers' identities. The school culture that promotes a good atmosphere (Esteve, 2006) is a favourable condition for developing a strong TI.

The dialogical interaction between teachers' unfavourable working conditions and their emotional involvement in the educational environment contribute, as immediate contextual factors, to the construction of EFL teacher identity. Because of this relationship, teachers experience opposite feelings resulting in motivation or demotivation, commitment or disenchantment, self-confidence or hopelessness, lights or shadows.

\subsection{Implications and Future Research}

Education reforms sometimes do not consider teachers' identities regarding their motivation efficacy, commitment, job satisfaction, effectiveness (Day, 2002) and needs. One of the main actors amid education scenario is the teacher. From the present study, three issues should be considered in reform contexts: strengthen school culture (micro context), avoid bureaucracy, and support teachers with training (macro context). Teacher identity research contributes to the knowledge of the topic from different perspectives and context, and teacher formation programmes and policy makers.

Sociocultural theory considers personal (psychological) and contextual (social) factors in TI construction. In the present investigation, only micro and macro external or contextual factors were considered; however, personal factors such as teachers' prior constructs, social positioning and professional self-image are topics for further research related to EFL TI.

\section{References}

Atkinson, D. (2004). Theorising how student teachers form their identities in initial teacher education. British Educational Research Journal, 30(3), 379-394. https://doi.org/10.1080/01411920410001689698

Avalos, B. (2010). Teacher identity construction in reform driven contexts: A Chilean study. Ejournal of all India Association for Educational Research, 22(2), 15-37.

Beauchamp, C., \& Thomas, L. (2009). Understanding teacher identity: an overview of issues in the literature and implications for teacher education. Cambridge Journal of Education, 39(2), 175-189. https://doi.org/10.1080/03057640902902252

Beauchamp, C., \& Thomas, L. (2011). Understanding new teachers' professional identities through metaphor. Teaching and Teacher Education, 27, 762-769. https://doi.org/10.1016/j.tate.2010.12.007

Beijaard, D., Meijer, P., \& Verloop, N. (2004). Reconsidering research on teachers' professional identity. Teaching and Teacher Education, 20, 107-128. https://doi.org/10.1016/j.tate.2003.07.001

Beltman, S., Glass, C., Dinham, J., Chalk, B., \& Nguyen, B. (2015). Drawing identity: Beginning pre-service teachers' professional identities. Issues in Educational Research, 25(3), 225-245.

Blumer, H. (1969). Symbolic interactionism: Perspective and Method. Englewood Cliffs: Prentice Hall.

Bonilla, C., \& Tejeda-Sánchez. (2016). Unanswered Questions in Colombia’s Foreign Language Education Policy. Profile, 18(1), 185-201. https://doi.org/10.15446/profile.v18n1.51996

Chacón, C. (2010). Acento e identidad profesional en la formación del docente de inglés: Una perspectiva crítica. Paradigma, 31(2), 25-36.

Chong, S. (2011). Development of teachers' professional Identities: From pre-service to their first year as novice teachers. KEDI Journal of Educational Policy, 8(2), 219-233. 
Cross, R. (2006). Identity and language teacher education: The potential for socio-cultural perspectives in researching language teacher identity. Presented at the Annual Conference of the Australian Association of Educational Research: Engaging Pedagogies, 27-30 November, 2006, University of South Australia, Adelaide.

Day, C. (2002). School reform and transitions in teacher professionalism and Identity. International Journal of Educational Research, 37(8), 677-692. https://doi.org/10.1016/S0883-0355(03)00065-X

Day, C. (2004). A passion for teaching. London, UK: Routledge Falmer. https://doi.org/10.4324/9780203464342

Day, C., Kington, A., Sammons, P., \& Stobart, G. (2006) The personal and professional selves of teachers: stable and unstable identities. British Educational Research Journal, 32(4), 601-616. https://doi.org/10.1080/01411920600775316

Day, C. (2012). New Lives of Teachers. Teacher Education Quarterly, 39(1), 7-26.

Esteve, J. (2006). Las Emociones en el Ejercicio Práctico de la Docencia. Teoría Eduacional Ediciones Universidad de Salamanca, 18, 85-107.

Flum, H., \& Kaplan, A. (2012). Identity formation in educational settings: A contextualized view of theory and research in practice. Psychological Studies in Education, 37(3), 240-245. https://doi.org/10.1016/j.cedpsych.2012.01.003

Glaser, B., \& Straus, A. (1967). Discovery of grounded theory. Chicago: Aldine.

Hall, D., \& McGinity, R. (2015). Conceptualizing Teacher Professional Identity in Neoliberal times: Resistance. Compliance and Reform. Education policy analysis archives, 23, 88. https://doi.org/10.14507/epaa.v23.2092

Hoban, G. (2007). Considerations for designing coherent teacher education programs. In En J. Butcher \& L. McDonald (Eds.), Making a difference: Challenges for teachers, teaching and teacher education (pp. 173-187). Rotterdam: Sense Publishers.

Hoffman-Kipp, P. (2008). Actualizing Democracy: The Praxis of Teacher Identity Construction. Teacher Education Quarterly, 35(3), 151- 164.

Katsuno, M. (2012). Teachers' Professional Identities in an Era of Testing Accountability in Japan: The Case of Teachers in Low-Performing Schools. Education Research International, 2012, 1-8. https://doi.org/10.1155/2012/930279

Kim, T., \& Dang A. (2013). Identity in activity: Examining teacher professional identity formation in the paired-placement of student teachers. Teaching and Teacher Education, 30, 47-59. https://doi.org/10.1016/j.tate.2012.10.006

Kvale, S. (1996). InterViews - An introduction to qualitative research interviewing. Thousand Oaks, CA: Sage.

LGE (2009). Ley General de Educación. Ministerio de Educación - Chile. Retrieved from Ministry of Education website: http://www.leychile.cl/Navegar?idNorma=1006043

LOCE (1990). Ley Orgánica Constitucional de Enseñanza. Ministerio de Educación Pública - Chile. Retrieved from Ministry of Education website http://www.leychile.cl/Navegar?idNorma=30330

Mead, G. (1934). Mind, Self and Society. En A. Strauss, (1956). George Herbert Mead on Social Psychology. Selected Papers. Chicago: The University of Chicago Press.

Menter, I. (2010). Teachers -formation, training and identity: a literature review. Creativity, Culture and Education. Great North House. Recuperado de http://www.creativitycultureeducation.org/researchimpact/literature-reviews/

Ministerio de Educación. (2015). La formación de docentes de inglés: SEMINARIOS 2012-2014. Seminarios Formación Inicial docente. British Council y Ministerio de Educación, Chile.

Mora, A., Trejo, N. P., \& Roux, R. (2013). Can ELT in higher education be successful? The current status of ELT in Mexico. TESL-EJ, 17(1), 1-26. Retrieved from http://www.tesl-ej.org/wordpress/issues/volume17/ej65/ej65a2/.

Olsen, B. (2008). Introducing Teacher Identity and This Volume. Teacher Education Quarterly, 35, 3-6.

Penuel, W., \& Wertsch, V. (1995). Vygotsky and Identity Formation: A sociocultural Approach. Educational Psychologist, 30(2), 83-92. https://doi.org/10.1207/s15326985ep3002_5

Prytula, M., \& Hellsten, L. (2012). Examining the Development of Teacher Identity through Cohort Induction Modelsi in The Context of Reform. Canada: Early Data. 
Robertson, S. (2000). A Class Act: Changing Teachers' Work, the State and Globalisation. New York and London: Falmer Press.

Sachs, J. (2005). Teacher education and the development of professional identity: Learning to be a teacher. En P. Denicolo \& M. Kompf (Eds.), Connecting policy and practice: Challenges for teaching and learning in schools and universities (pp. 5-21). Oxford: Routledge.

Smagorinsky, P., Cook, L., Moore, C., Jackson, A., \& Fry, P. (2004). Tensions in learning to teach: Accommodation and the development of a teaching identity. Journal of Teacher Education, 55(1), 8-24. https://doi.org/10.1177/0022487103260067

Strauss, A., \& Corbin, J. (1998). Basics of Qualitative Research: Techniques and Procedures for Developing Grounded Theory (2nd ed.). Thousand Oaks: Sage.

Tsui, M. (2007). Complexities of Identity Formation: A Narrative Inquiry of an EFL Teacher. TESOL Quarterly, 41(4), 657-680. https://doi.org/10.1002/j.1545-7249.2007.tb00098.x

Varghese, M., Morgan B., Johntson B., \& Johnson, K. (2005). Theorizing Language Teacher Identity: Three Perspectives and Beyond. Journal of Language, Identity, and Education, 4(1), 21-44. https://doi.org/10.1207/s15327701jlie0401_2

Vygotsky, L. (1978). Mind in society: The development of higher psychological processes. Cambridge. En Penuel, W. \& Wertsch, V. (1995). Vygotsky and Identity Formation: A sociocultural Approach. Educational Psychologist, 30(2), 83-92.

Wenger, E. (1998). Communities of Practice: Learning, Meaning, and Identity. New York: Cambridge University Press. https://doi.org/10.1017/CBO9780511803932

Zembylas, M. (2003). interrogating "teacher identity": Emotion, resistance, and self-formation. Educational Theory, 53, 107-127. https://doi.org/10.1111/j.1741-5446.2003.00107.x 